\section{www.czasopisma.pan.pl \\ ARCHIVES \\ of \\ FOUNDRY ENGINEERING}

DOI: 10.1515/afe-2017-0077
ISSN (2299-2944)

Volume 17

Issue 2/2017

\title{
Reducing the Negative of the Iron in the Alloy Based on Al-Si-Mg by Manganese
}

\author{
R. Podprocká ${ }^{a, *}$, D. Bolibruchová ${ }^{a}$, M. Chalupová ${ }^{b}$ \\ ${ }^{a}$ Department of Technological Engineering, Faculty of Mechanical Engineering, University of Žilina, Slovakia \\ ${ }^{b}$ Department of Materials Engineering, Faculty of Mechanical Engineering, University of Žilina, Slovakia \\ *Corresponding author. E-mail address: radka.podprocka@fstroj.uniza.sk
}

Received 14.03.2017; accepted in revised form 22.05.2017

\begin{abstract}
In Al-Si alloy the iron is the most common impurity and with presence of other elements in alloy creates the intermetallic compounds, which decreases mechanical properties and increases of porosity. The cause of the negative effect of intermetallic particles on the mechanical properties is that it is more easily break off the tension load as the aluminium matrix or small particles of silicon. By adding suitable alloying elements, also known as iron correctors, is possible to reduce this harmful effect.

In the article is evaluated influence of manganese on microstructure with performed EDX analysis selected intermetallic phases and tensile test and measurement of length of $\mathrm{Al}_{5} \mathrm{FeSi}$ phase. For realization experiments was used $\mathrm{AlSi} 7 \mathrm{Mg} 0.3$ alloy with increased iron content. Manganese was added in the amount 0.3 wt. \%, 0.6 wt. \%, 0.8 wt.\% and 1,2 wt. \%. From performed measurements it has been concluded, that increased amount of manganese, i.e. $\mathrm{Mn} / \mathrm{Fe}$ ratio, does not have significant influence on mechanical properties $\mathrm{AlSi} 7 \mathrm{Mg} 0.3$ alloy in the melted state.
\end{abstract}

Keywords: AlSi7Mg0.3 alloy, Manganese, Iron intermetallic phases

\section{Introduction}

At the present time, in the production of castings for the automotive industry is a key requirement reducing of costs with purpose to increase competitiveness and maintaining high quality castings. For these purposes can be used secondary alloys Al-Si, but it is necessary to take into account their specifics properties. The properties of the secondary aluminium alloys are comparable to primary alloys, but important attention must be paid due to the higher iron content. Iron with the presence of other elements in the alloy creates intermetallic compounds which have negative influence especially on the mechanical properties. Intermetallic phase based on iron nucleating during solidification may occur in different morphologies such as: $\beta$-Al ${ }_{5} F e S i-n e e d l e s, ~ \alpha-$ $\mathrm{Al}_{15}(\mathrm{Fe}, \mathrm{Mn})_{3} \mathrm{Si}_{2}$-Chinese script or skeleton formations, polyendral crystals, $\mathrm{Al}_{8} \mathrm{FeMg}_{3} \mathrm{Si}_{6}$ (known as $-\pi$ ) [1-3].
The $\mathrm{Al}_{5} \mathrm{FeSi}$ phase ( $\beta$-phase) is considered as the most observed compound which is present in the form of thin plates or rods. This phase causes a decrease of elongation due to higher brittleness, reduces fatigue and increases of porosity because it extends into the flowing melt during solidification [4-6].

To reducing negative impact of excluded intermetallic phases morphology is used several methods. The most used method is the addition of suitable alloying elements into the melt, which change the needle phases based on iron to more suitable, less harmful form - e.g: Mn, Cr, Co, K. From these elements in technical practice is most applied manganese. The recommended ratio of addition a manganese to eliminate the harmful effects of iron, according to several authors $\mathrm{Mn}: \mathrm{Fe}=1: 2$ or if an iron amount exceeds a value of the mass fraction $\mathrm{w}=0.45 \%$, the recommended addition of $\mathrm{Mn}$ should not be lower than half of the iron amount $[7,8]$. However, to determine the correct ratio of $\mathrm{Mn} / \mathrm{Fe}$ according to previous research is not exactly known. 
Manganese with reducing of amount $\beta$-phase $\left(\mathrm{Al}_{5} \mathrm{FeSi}\right)$ increases the corrosion resistance of the alloys based on $\mathrm{Al}-\mathrm{Si}-\mathrm{Mg}$, reduces the porosity and increases the fatigue resistance of castings. The morphology of the phases after addition of manganese is dependent on the chemical composition of the alloy and the cooling rate $[9,10]$. The manganese in the usual amount doesn't affect casting properties. As regards secondary alloys high iron content combined with manganese and chromium can cause sludge formations called "sludge" phases. These phases occur in maintaining the alloy at a relatively low temperature. Sludge phases can not be re-melted by raising the temperature, therefore it is necessary to avoid preventively their occurrence by keeping the melt at a sufficiently high temperature.

\section{Materials and experiments methodology}

Experimental part of work deals with the analysis of the influencing of manganese for elimination higher amount of iron in the alloy AlSi7Mg0.3. The chemical composition of the alloy is given in Table 1.

The content of iron in the alloy $\mathrm{AlSi} 7 \mathrm{Mg} 0.3$ is approximately 0.1 wt.\%. This value is insufficient for describing the effect of iron and next application of manganese. The alloy was alloyed by master alloy AlFe10 to achieve higher amount of iron about 0.7 wt.\%. The manganese was added in the form of master alloy AlMn20 in an amount: 0.3 wt.\%, 0.6 wt. \%, 0.8 wt.\%, 1.2 wt.\%. The chemical composition of these melts is in Table 2. The melting was performed in electric resistance furnace, controlled by regulator. The alloys were poured into a metal mould preheated to a temperature of $200 \pm 5^{\circ} \mathrm{C}$ at $760 \pm 5^{\circ} \mathrm{C}$. The melt was not further modified, grain refined or purified. During the melting was only removed oxide films on the surface of the melt.

Table 1

Chemical composition (wt.\%) of alloy AlSi7Mg0.3

\begin{tabular}{llllllllll}
$\mathrm{Si}$ & $\mathrm{Fe}$ & $\mathrm{Cu}$ & $\mathrm{Mn}$ & $\mathrm{Mg}$ & $\mathrm{Zn}$ & $\mathrm{Ti}$ & $\mathrm{Sr}$ & $\mathrm{Al}$ & $\mathrm{Mn} / \mathrm{Fe}$ \\
\hline 7,093 & 0,099 & $<0,0020$ & 0,072 & 0,38 & 0,0054 & 0,18 & 0,015 & 92,14 & 0,48 \\
\hline
\end{tabular}

Table 2.

Chemical composition (wt.\%) of alloy AlSi7Mg0.3with increased iron content after adding of manganese

\begin{tabular}{cccccccccccc}
\hline $\begin{array}{c}\text { Additive } \mathrm{Mn} \\
\text { (wt.\%) }\end{array}$ & $\mathrm{Si}$ & $\mathrm{Fe}$ & $\mathrm{Cu}$ & $\mathrm{Mn}$ & $\mathrm{Mg}$ & $\mathrm{Zn}$ & $\mathrm{Ti}$ & $\mathrm{Sr}$ & $\mathrm{Al}$ & $\mathrm{Mn} / \mathrm{Fe}$ \\
\hline 0,3 & 7,046 & 0,743 & $<0,0020$ & 0,474 & 0,381 & 0,005 & 0,139 & 0,0083 & 91,18 & 0,64 \\
\hline 0,6 & 6,916 & 0,753 & $<0,0020$ & 0,699 & 0,36 & 0,0059 & 0,134 & 0,0043 & 91,1 & 0,93 \\
\hline 0,8 & 7,083 & 0,684 & 0,0066 & 0,704 & 0,35 & 0,0098 & 0,141 & 0,0077 & 90,98 & 1,03 \\
\hline 1,2 & 6,560 & 0,635 & 0,0034 & 1,079 & 0,359 & 0,0049 & 0,139 & 0,0097 & 91,18 & 1,7 \\
\hline
\end{tabular}

\section{Results}

The influence of manganese in the alloy with higher iron content was evaluated on the samples prepared by standard metallographic procedure. Evaluated samples for microstructure observation of the light microscope were etched $20 \mathrm{ml} \mathrm{of} \mathrm{H}_{2} \mathrm{SO}_{4}+$ $100 \mathrm{ml} \mathrm{H}_{2} \mathrm{O}$.

The tensile test was performed according STN 420310 for a maximum load of $20 \mathrm{kN}$ and at a constant crosshead displacement rate of $2 \mathrm{~mm} / \mathrm{min}$ and a test bar with a diameter of $10 \mathrm{~mm}$. As a hardness measurement method was used method according to Brinell. The red line on graphs (Fig. 5-7) shows the minimum required values of mechanical properties for $\mathrm{AlSi} 7 \mathrm{Mg} 0.3$ according of EN 1706.

\subsection{Microstructure}

The microstructure of the based alloy AlSi7Mg0.3 is formed by $\alpha$-phase dendrites, silicon eutectic and iron based intermetallic phases excluded in the form of small particles of Chinese script.
In the microstructure of alloy with increased amount of iron 0.7 wt. \%, but without added manganese is mostly iron based particles in the form of needle of $\mathrm{Al}_{5} \mathrm{FeSi}$ phase (Fig. 1).

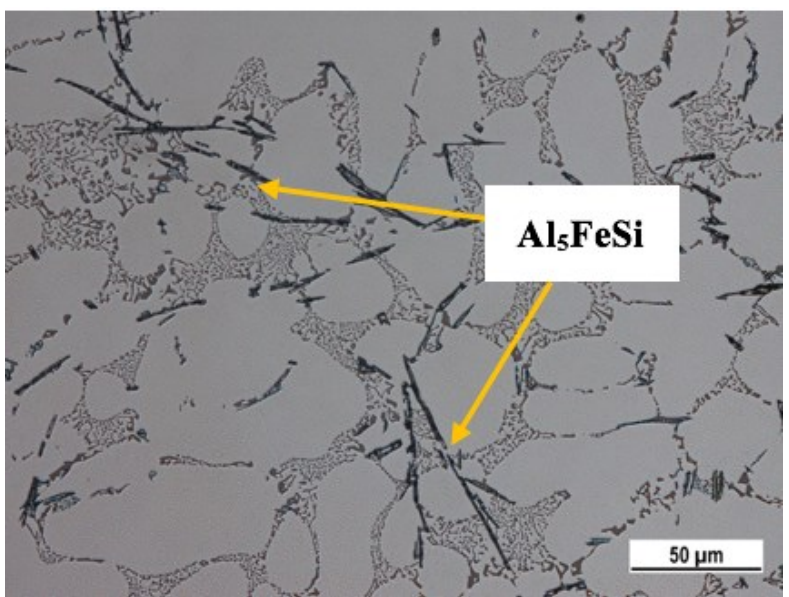

Fig. 1. Microstructure of AlSi7Mg0.3 alloy with increased iron content 
Manganese addition in amount of 0.3 wt.\% into alloy with increased iron content didn't lead to change of morphology needle phase of $\mathrm{Al}_{5} \mathrm{FeSi}$ to the less harmful shape. In the structure of the alloy were located thin needles form of $\mathrm{Al}_{5} \mathrm{FeSi}$ phase uniformly distributed in the aluminium matrix. The chemical composition of
$\mathrm{Al}_{5} \mathrm{FeSi}$ phase is shown on Fig. 2. The results of EDX analysis confirmed the presence of manganese in the structure of the particles. From the results of chemical composition is clear, that it is a $\mathrm{Al}_{5} \mathrm{FeSi}$ phase.
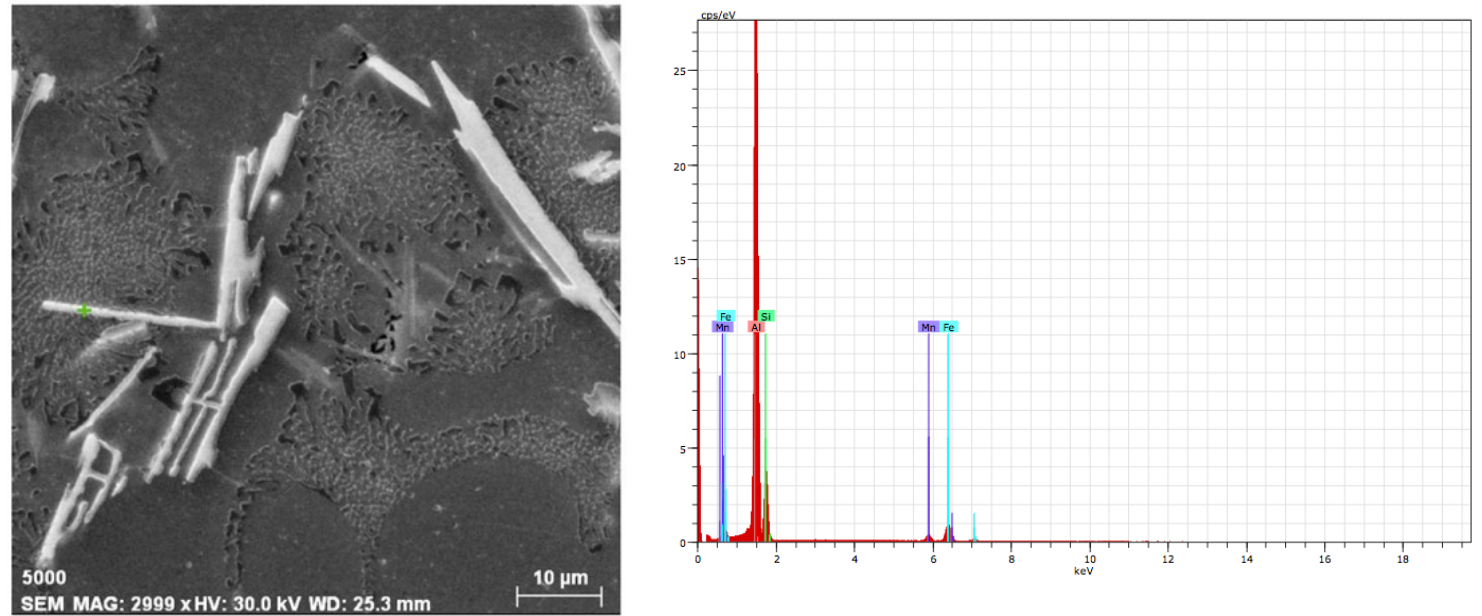

Fig. 2. EDX analysis needle of $\mathrm{Al}_{5} \mathrm{FeSi}$ phase

Manganese amount of 0.6 wt. \% and 0.8 wt.\% caused a change in the morphology needle of $\mathrm{Al}_{5} \mathrm{FeSi}$ phase into smaller skeleton particles, or Chinese script (Fig. 3). After adding 1.2 wt.\% of Mn

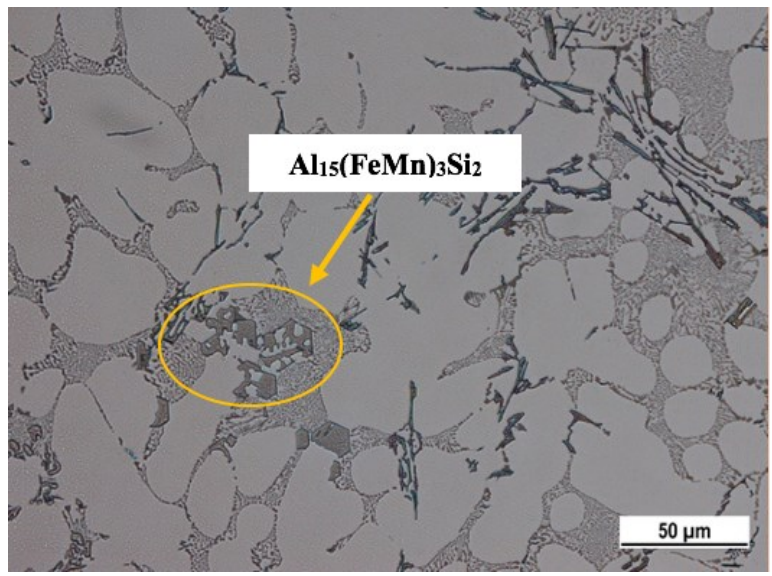

a) in the microstructure rarely needle of $\mathrm{Al}_{5} \mathrm{FeSi}$ phase has been occurred. In the structure of the alloy were mostly presented skeleton formation phases $\mathrm{Al}_{15}(\mathrm{Fe}, \mathrm{Mn})_{3} \mathrm{Si}_{2}$.

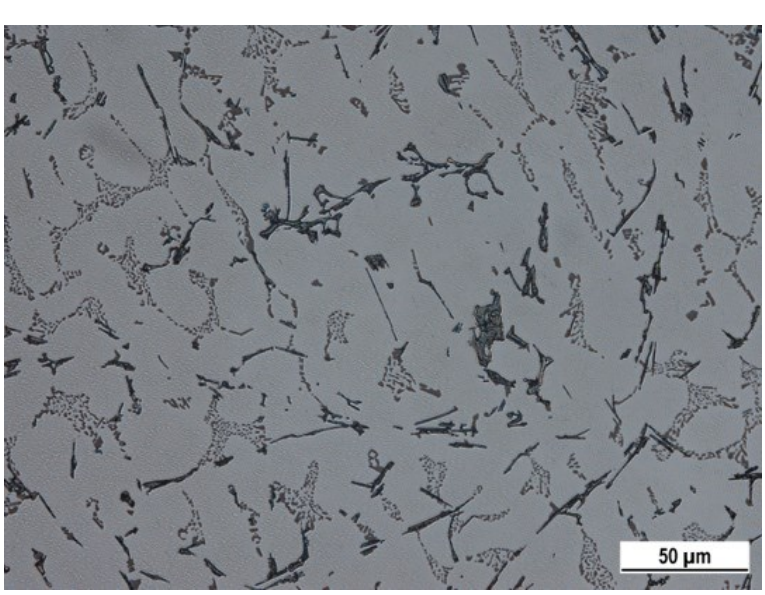

b)

Fig. 3. Microstructure of AlSi7Mg0.3 alloy with increased iron content with addition: a) 0.6 wt. \% Mn, b) 0.8 wt. $\%$ Mn

Mutual combination of higher amount of iron along with manganese at the same time also caused the formation "sludge phases". These phases are undesirable in the structure of alloy, because of their high hardness and the melting temperature, since they reduce the fluidity of the metal and decrease mechanical properties. The chemical composition of the "sludge phase" is shown on Fig. 4. 

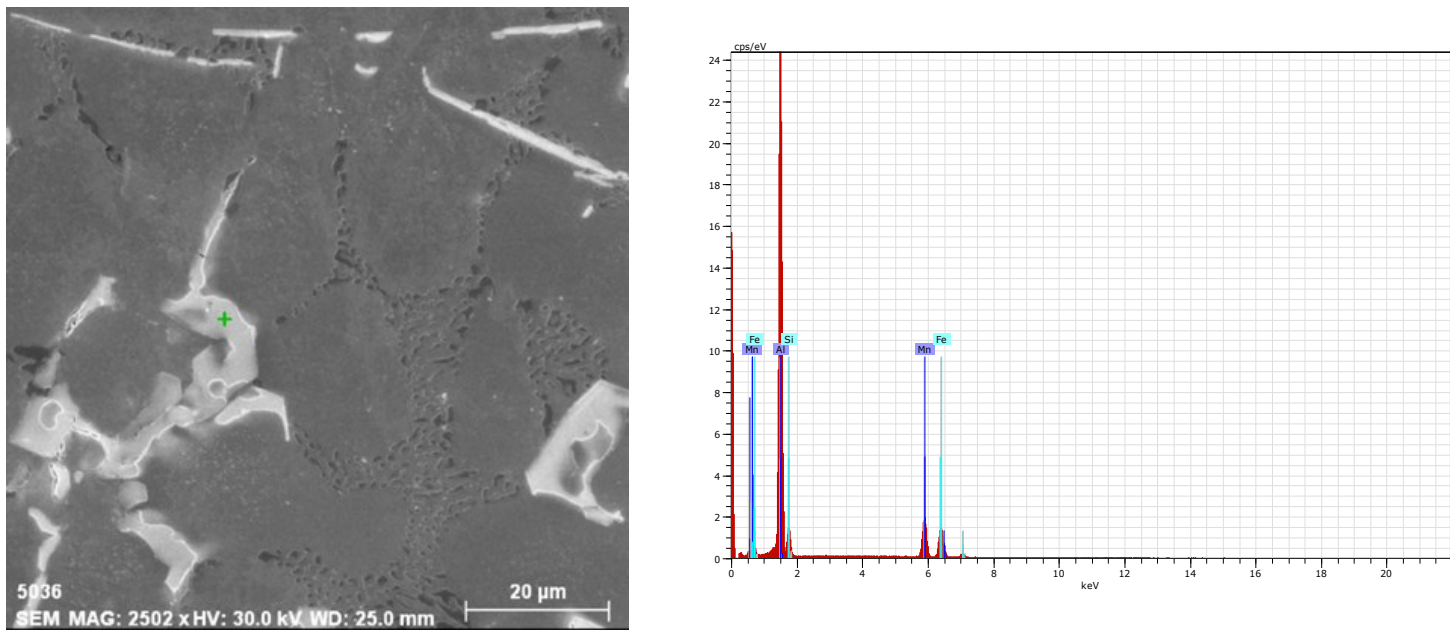

Fig. 4. EDX analysis of "sludge phase"

For better description of manganese effect in the alloy AlSi7Mg0.3 with a higher content of iron was made measuring the phase of $\mathrm{Al}_{5} \mathrm{FeSi}$ by $500 \times$ magnification and detecting SDAS factor for each sample. The results of measurement are given on Table 3.

Table 3.

Results of measurements of length of $\mathrm{Al}_{5} \mathrm{FeSi}$ phase and SDAS factor

\begin{tabular}{ccc}
\hline $\begin{array}{c}\text { Additive } \mathrm{Mn} \\
{[\mathrm{wt} . \%]}\end{array}$ & $\begin{array}{c}\text { Length of } \mathrm{Al}_{5} \mathrm{FeSi} \\
\text { phase }[\mu \mathrm{m}]\end{array}$ & SDAS factor $[\mu \mathrm{m}]$ \\
\hline 0 & 27,97 & 20,7 \\
\hline 0,3 & 13,49 & 18,5 \\
\hline 0,6 & 13,315 & 20,3 \\
\hline 0,8 & 13,435 & 20,2 \\
\hline 1,2 & 13,03 & 19,4 \\
\hline
\end{tabular}

From the measured lengths of intermetallic phases $\mathrm{Al}_{5} \mathrm{FeSi}$ can be concluded, that adding of $0.3 \mathrm{wt}$. $\% \mathrm{Mn}$ into the alloy is sufficient to significant shorten phases length average about $45 \%$.

\subsection{Mechanical properties}

The Fig. 5 presents relationship between the tensile strength and the quantity of added manganese. The increase of manganese or $\mathrm{Mn} / \mathrm{Fe}$ in the alloy didn't lead to an increase of a tensile strength. The highest value of the tensile strength was achieved after the addition of the Mn amount of $0.6 \mathrm{wt} . \%$ probably because of the presence of the skeleton particles in the structure of the alloy. The relationship between the elongation and manganese presents the Fig. 6. The highest value of elongation was achieved after the addition of the Mn of 0.6 wt. $\%$ also. The further increase of manganese, or $\mathrm{Mn} / \mathrm{Fe}>1.03$ leads to decrease of elongation. The measurements of hardness showed the increasing the manganese content in the alloy with higher content of iron leads in to a slight increase of a hardness. Higher hardness can be caused by the presence of sludge formations in the structure of alloys, that exhibit high hardness $800-1000 \mathrm{HV}$, but also iron phases which are distributed in the structure of the alloy [1]. The measurements of a hardness are shown on Fig. 7.

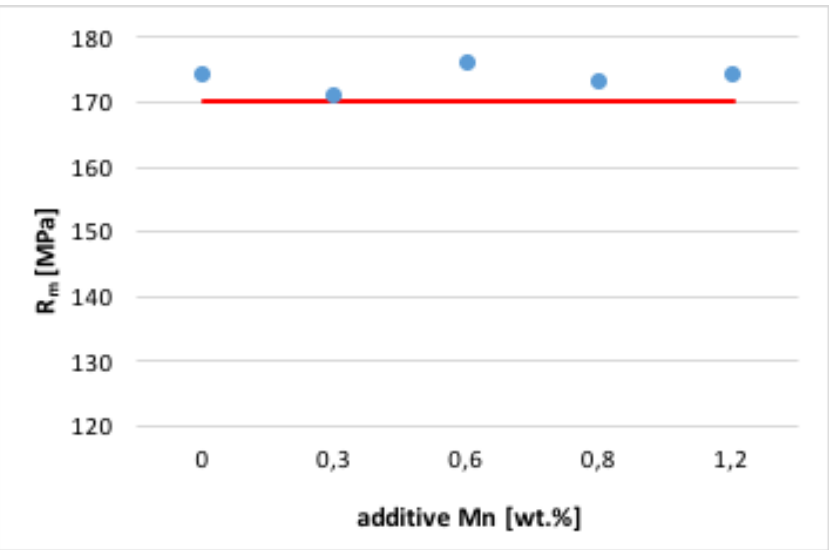

Fig. 5. Results of tensile strength of AlSi7Mg0.3 alloy with increased iron content with different additive of manganese

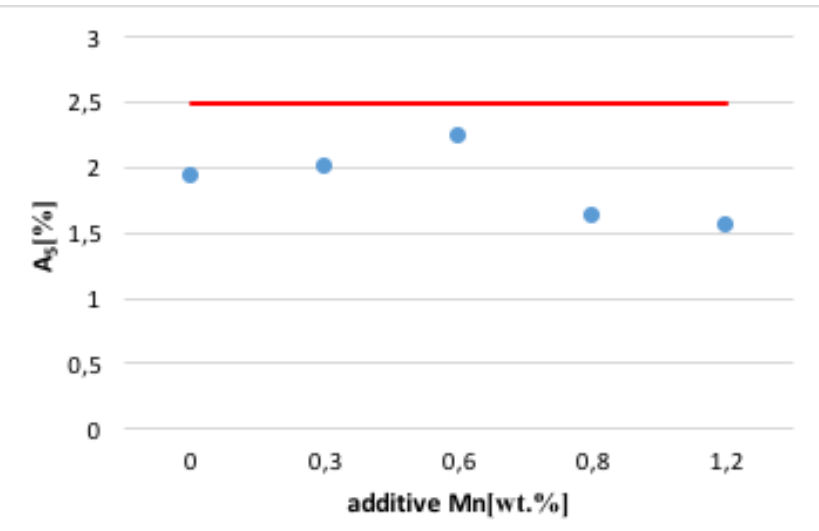

Fig. 6. Results of elongation of $\mathrm{AlSi} 7 \mathrm{Mg} 0.3$ alloy with increased iron content with different additive of manganese 


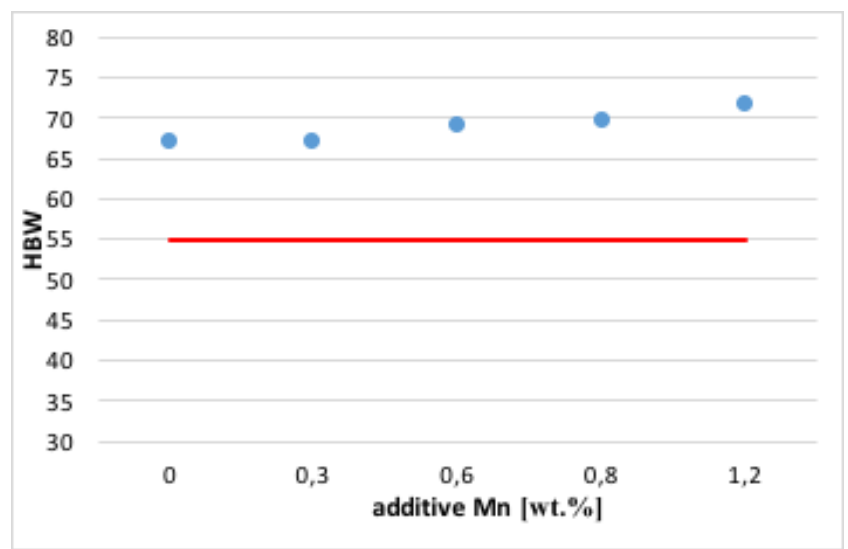

Fig. 7. Results of hardness of AlSi7Mg0.3 alloy with increased iron content with different additive of manganese

\section{Conclusions}

The effect of manganese in the alloy AlSi7Mg0.3 with increased iron content confirmed the positive influence of the elimination of harmful needle of $\mathrm{Al}_{5} \mathrm{FeSi}$ phase. The addition of manganese leads to a significant shortening of $\mathrm{Al}_{5} \mathrm{FeSi}$ phase an average of $45 \%$. The increasing the amount of manganese in the alloy, respectively $\mathrm{Mn} / \mathrm{Fe}$ has no significant effect on mechanical properties. The hardness value is slightly increasing with increasing manganese content in the alloy. It can be stated, that the addition of manganese in the alloy with $\mathrm{Mn} / \mathrm{Fe}>0.93$ leads to change of morphology from needle $\mathrm{Al}_{5} \mathrm{FeSi}$ phase to the form of Chinese script or skeleton particles. The higher Fe content in the alloy (controlled contamination) about 0.7 wt. \% doesn't have such significant influence on the mechanical properties of the alloy in the melted state (see the results of mechanical characteristics of Fig. 5-7), because the relative amounts of manganese can be relatively efficiently corrected.

\section{References}

[1] Taylor, J.A. (2012). Iron-containing intermetallic phases in Al-Si based casting alloys. Procedia Materials Science. 1, 19-33.

[2] Tillová, E., Chalupová, M. (2009). Structural analysis of AlSi cast alloys. Žilina: EDIS.

[3] Cao, X. \& Campbell, J. (2006). Morphology of $\mathrm{Al}_{5} \mathrm{FeSi}$ Phase in Al-Si Cast Alloys. Materials Transactions. 47(5), 1303-1312.

[4] Taylor, J.A. (2004). The effect of iron in Al-Si casting alloys. In 35th Australian Fondry Institute National Conference, 2004, (pp. 148-157).

[5] Bolibruchová, D. \& Žihálová, M. (2014). Vanadium influence on iron based intermetallic phases in AlSi6Cu4. Archives of Metallurgy and Materials, 59 (3), 1029-1032.

[6] Shabestari, S.G. (2002). Effect of $\mathrm{Mn}$ and $\mathrm{Sr}$ on intermetallics in Fe-rich eutectic Al-Si alloy. International Journal of Cast Metals Research.

[7] Fortini, et al. (2016). On influence of Mn and Mg additions on tensile properties, microstructure and quality index of the A356 aluminum foundry alloy. $21^{\text {st }}$ European Conference on Fracture. Procedia Structural Integrity. 2, (pp. 2238-2245).

[8] Elsharkawi, et al. (2010). Effects of Mg, Fe, Be additions and solutions heat treatment on the $\pi$-AlMgFeSi iron intermetallic phase in Al-7Si-Mg alloys. Journal of Materials Science. 45, 1528-1539.

[9] Bidmeshki, et. al. (2016). Effect of Mn addition of Fe-rich intermetallics morphology and dry sliding wear investigation of hypereutectic Al-17,5\% Si. Journal of Materials Research and Technology. 5 (3), 250-258.

[10] Zhang, et. al. (2013). Effect of the $\mathrm{Mn} / \mathrm{Fe}$ ratio and cooling rate on the modification of $\mathrm{Fe}$ intermetallic compounds in cast A356 based alloy with different Fe contents. Materials Transactions. 54 (8), 1484-1490. 